\title{
Diálogos entre a América Latina e o Curdistão: aproximação entre movimentos anticoloniais do Sul Político ${ }^{1}$
}

\author{
Diálogos entre América Latina y el Kurdistán: acercamiento entre \\ movimientos anticoloniales del Sur Político
}

\section{Dialogues between Latin America and Kurdistan: approximation between anticolonial movements of the Political South}

\author{
Guilherme Borges Almeida² \\ Laura Marquesan Eschberger ${ }^{3}$
}

\begin{abstract}
Resumo
O presente estudo busca estabelecer um diálogo entre os movimentos anticoloniais do Sul Político, tendo como base o movimento de Rojava e os movimentos latino-americanos explicitados pela Teoria Decolonial. Primeiramente, objetiva-se identificar como a Teoria Decolonial cria instrumentos para pensar o movimento curdo como sendo uma iniciativa questionadora da modernidade. Ademais, o trabalho tem o intuito de ressaltar a importância de não restringir as lutas anticoloniais no ideário do Estado-nação, assim como enfatizar as estratégias práticas desenvolvidas por estes movimentos no processo de socialização do poder, sendo esta uma das críticas mais substanciais à modernidade/colonialidade. Em suma, o cerne do trabalho reside em apontar como esses movimentos se articularam em uma tentativa de ressignificar o discurso hegemônico tendo como base epistemologias e cosmologia locais não-ocidentalizadas.
\end{abstract}

Palavras-chave: América Latina; Curdistão; decolonialismo; lutas anticoloniais; modernidade; Rojava.

\section{Resumen}

El presente estudio busca establecer un diálogo entre los movimientos anticoloniales del Sur Político, teniendo como base el movimiento de Rojava y los movimientos latinoamericanos explicitados por la Teoría Decolonial. Primero, se objetiva identificar cómo la Teoría Decolonial crea instrumentos para pensar el movimiento kurdo como una iniciativa cuestionadora de la modernidad. Además, el trabajo tiene el propósito de resaltar la importancia de no restringir las luchas anticoloniales en el ideario del Estado-nación, así como enfatizar las estrategias prácticas desarrolladas por estos movimientos en el proceso de socialización del poder, siendo esta una de las críticas más sustanciales a la modernidad/colonialidad. En suma, el núcleo del trabajo reside en señalar cómo estos movimientos se articularon en un intento de resignificar el discurso hegemónico teniendo como base epistemologías y cosmología locales no occidentalizadas.

Palabras claves: América Latina; Kurdistán; decolonialismo; luchas anticoloniales; modernidad; Rojava.

1 Artigo apresentado no Simpósio Temático (II Seminário Latino-americano de estudos em cultura, integração e multiculturalismo na América Latina: perspectiva histórica e desafios no contexto atual) durante o II Seminário Latino-Americano de Estudos em Cultura - SEMLACult em Foz do Iguaçu/PR, Brasil, 2018.

2 (Mestrando em Integração Contemporânea da América Latina; Universidade Federal da Integração LatinoAmericana - UNILA; Foz do Iguaçu, Paraná, Brasil; guilherme.borgesalmeida@gmail.com).

3 (Graduada em Relações Internacionais; Escola Superior de Propaganda e Marketing de Porto Alegre - ESPM-

Sul; Porto Alegre, Rio Grande do Sul, Brasil; laura.marquesan@ gmail.com). 


\begin{abstract}
This project aims to establish a dialogue between anticolonial movements of the Political South, based on the Rojava movement and the latin american movements pointed out by the Decolonial Theory. First of all, it seeks to identify how the Decolonial Theory creates instruments to think the Kurdish movement as being a questioning initiative of the modernity. In addition, this paper aims to emphasize the importance of not restricting anticolonial struggles in the ideology of the State-nation and emphasize as well the practical strategies developed by these movements in the process of the socialization of power, which is one of the most substantial critics of the modernity/coloniality. In sum, the core of this work lies in pointing out how these movements have articulated in an attempt to re-signify the hegemonic discourse on the basis of non-Western local epistemologies and cosmologies.
\end{abstract}

Keywords: Latin America; Kurdistan; decoloniality; anticolonial struggles; modernity; Rojava.

\title{
1. Introdução
}

Considerando que o fim do colonialismo político não significou a supressão das relações sociais desiguais, o que Quijano denominou de colonialidade do saber e do poder, percebe-se que o capitalismo global atual logrou desenvolver uma dominação polifacetada - está presente tanto nos projetos políticos, sociais e econômicos, como também no modelo civilizatório. Parte dessa dominação se deu justamente com o que foi chamado por Boaventura (2013) de epistemicídio, ou seja, um anulamento dos conhecimentos locais, tendo como ponto de partida a missão civilizadora do período colonial. Essa pretensão de criar um mundo mais homogêneo e monocultural, respaldados em um ideal universalista, contou com um aparato institucional Estados, universidades, relações sociais e organizativas. Como apontado por Boaventura e Maria Meneses (2013): "toda experiência social produz e reproduz conhecimento e, ao fazê-lo, pressupõe uma ou várias epistemologias". Sendo assim, as epistemologias do sul buscam justamente denunciar essa supressão dos saberes do Sul como forma de rever essa colonialidade do saber e do poder. Ressaltando que o Sul se refere ao local metaforicamente concebido como sendo "o campo de desafios epistêmicos que busca rever os danos trazidos pelo capitalismo na sua relação com o capitalismo global" e não ao espaço geográfico.

Enfatizando a importância de se estudar as epistemologias do Sul e criar vasos comunicantes entre os saberes e lutas do Sul político, esse trabalho tem como objetivo geral explorar como a teoria decolonial latino-americana cria instrumentos para pensar o movimento do Curdistão como uma iniciativa questionadora da modernidade/colonialidade. Para atingir esse propósito, o trabalho também conta com os seguintes objetivos específicos: ressaltar a importância de estabelecer um diálogo entre diferentes lutas anticoloniais no Sul político; contextualizar o movimento decolonial na América Latina e a Revolução de Rojava no Curdistão como iniciativas questionadoras da modernidade/colonialidade; enfatizar a busca por estratégias práticas de socialização do poder como formas de realizar uma crítica ampla à 
modernidade; e ressaltar a importância de não restringir as lutas anticoloniais no Sul político ao âmbito do Estado-nação.

O trabalho pretende estabelecer uma relação entre a formulação teórica dos estudos decoloniais enquanto epistemologia fundada nas experiências subalternas latino-americanas e a Revolução de Rojava enquanto uma luta anticolonial. É importante destacar, no entanto, que não se pretende empregar a teoria decolonial como forma de explicar a realidade curda. Isso implicaria em negar a teoria decolonial como uma perspectiva formulada a partir da América Latina, assumindo-a como um ponto de partida não-situado epistemicamente e pretensamente neutro - ou seja, adotando a posição da linguagem científica da modernidade, chamada por Castro-Gómez (2003) de "hybris del punto cero". Argumenta-se, nesse artigo, que o Confederalismo Democrático do Curdistão poderia ser entendido como um desses movimentos de questionamento à modernidade surgidos no Sul Político.

Para tanto, retoma-se as principais críticas à modernidade/colonialidade levantadas pelos estudos decoloniais relacionando-as com as reflexões de autores curdos sobre o processo revolucionário da região. Nesse sentido, as formulações de Abdullah Öcalan $(2014 ; 2015)$ sobre o Confederalismo Democrático no Curdistão, sobre o capitalismo moderno e sobre o Estadonação serão um importante aporte para o diálogo com os estudos decoloniais latino-americanos. Öcalan é um dos fundadores do Partido dos Trabalhadores do Curdistão (PKK) e um dos maiores influenciadores da Revolução de Rojava, tendo escrito diversos livros sobre propostas de organização política no Curdistão desde que foi enviado para a prisão pelo governo da Turquia em 1999.

Esse projeto de Confederalismo Democrático é colocado como um movimento que não busca organizar-se nos moldes de um Estado, ou seja, não tem como objetivo fazer do Curdistão um Estado independente, mas sim criar uma confederação entre as comunidades curdas localizadas nos territórios da Turquia, Síria, Iraque e Irã (ÖCALAN, 2015, p. 23). Desta forma, o Curdistão busca evitar os problemas enfrentados por muitas lutas anticoloniais no TerceiroMundo ao se organizarem como um Estado-nação, como assinalado por Grosfoguel: "Em um mundo colonial a nação tem um caráter ambíguo. Por um lado serve para construir uma ficção de identidade homogênea na luta anticolonial, enquanto, por outro, instaura a ideologia moderna e eurocêntrica do Estado-nação" (GROSFOGUEL, 2012, p. 348).

Ademais, é imprescindível ressaltar a importância de estabelecer estes vasos comunicantes entre o Sul Político, respeitando as particularidades de cada região, mas compreendendo a complexidade do sistema hegemônico no qual se está inserido. Tendo isto em vista, percebe-se que manter as lutas anticoloniais dentro dos ideais eurocêntricos se mostra 
pouco eficaz e um tanto quanto paradoxal. A experiência de Rojava no Curdistão, assim como as lutas indígenas e afro-americanas na América Latina mostram a necessidade de construir um discurso a partir do olhar do subalterno, fazendo uma crítica à modernidade e à todo o sistema que a sustenta.

O desenvolvimento da sociedade, a organização social, a produção do conhecimento, a divisão do trabalho, as relações sociais, de gênero, a economia, a política foi pautada sob a perspectiva eurocêntrica (MIGNOLO, 2005). Neste sentido, será tratado em profundidade ao longo deste trabalho como a proposta de Rojava e a Teoria Decolonial buscam criar movimentos anticoloniais "afuera" do espectro de experiências ocidentalizadas, questionando as bases dessa estrutura hegemônica.

\section{Teoria Decolonial na América Latina}

A expansão europeia logrou institucionalizar, em escala global, a supremacia de uma classe - homem, branco, ocidental, cristão, europeu - sobre as outras, criando desenhos imperialistas nos quais a Europa teria a solução universal para os problemas do mundo. Apesar da ideia de colonização estar ligada a fatores como o domínio de territórios, a exploração do trabalho e a tentativa de converter os povos originários ao cristianismo fazendo com que se pense que há um período "pós-colonial”, estes foram apenas os meios pelo qual algo muito mais subjetivo e profundo foi desenvolvido. Distinguindo-se do colonialismo, a colonialidade diz respeito a lógica de dominação, sendo a modernidade o meio pela qual a colonialidade é executada. Sendo assim, não é possível dissociar um aspecto do outro, pois ambas têm uma relação constitutiva e não derivativa (MIGNOLO, 2005). Este processo culminou a criação de hierarquias globais, com a atribuição europeia de novas identidades geo-culturais ao resto do mundo, desenvolvendo um controle subjetivo, no qual há um domínio até mesmo o imaginário colonial, e instaurando uma estrutura de poder assimétrica.

Nesse sentido, aponta-se que pensar o capitalismo sob uma perspectiva puramente econômica é uma visão reducionista, quando, na realidade, o conceito trata de um sistema hegemônico que transcende as questões relacionadas à economia, estando impregnado nas relações de gênero, sexuais, raciais, espirituais, políticas, pedagógicas, epistemológicas - todas tendo como raiz a colonialidade/modernidade. Da mesma forma, a lógica da colonialidade foi desenvolvida a partir de diferentes aspectos, como o econômico, com o processo de apropriação de terras, exploração da mão-de-obra dos povos originários e o controle financeiro; o político, no que tange ao controle da autoridade e da jurisdição do território; o cívico, que trata do 
desenvolvimento de uma hierarquização de acordo com gênero e sexualidade - as relações homoafetivas eram comuns nas tribos indígenas, tal como a relação entre um gênero e outra era definida a partir do princípio da reciprocidade e não da dominação como o sistema capitalista impõe; e, por fim, o epistêmico, que diz respeito ao controle do conhecimento e da subjetividade (MIGNOLO, 2005). Todas essas questões serviram para projetar a lógica da colonialidade, cristalizando o ideário de que há uma resposta homogênea e universal aos problemas do mundo, e podem ser identificados ainda nos discursos desenvolvimentistas, por exemplo.

Nesse sentido, os estudos decoloniais se apresentam como uma iniciativa latinoamericana que busca olhar para as culturas periféricas que, mesmo sendo colonizadas, negadas e ignoradas pela modernidade eurocentrada, ainda conservam uma exterioridade a ela (DUSSEL, 2016). Voltam-se assim para forças sociais que surgem entre os dominados e os que questionam o padrão de poder da modernidade, tendo maior expressão na América Latina os movimentos indígenas e afrolatinoamericanos (QUIJANO, 2006). A insurgência de movimentos sociais vindos desses grupos, com estratégias práticas a partir do lugar do subalterno e das suas experiências, cria novas respostas e alternativas ao sistema hegemônico. Estes, por sua vez, assumem um caráter anti-imperialista, questionando os pilares fundacionais da modernidade (GROSFOGUEL, 2012).

Grosfoguel (2008) aponta também que uma alternativa às universalidades abstratas das epistemologias eurocêntricas seria a diversidade anticapitalista descolonial universal radical. Para o autor, o universalismo eurocentrado diluiu as particularidades locais das lutas contra o patriarcado, o capitalismo, a colonialidade e a modernidade. Sendo assim, esse projeto de libertação, visando englobar as múltiplas especificidades locais, deveria ser uma fusão entre a transmodernidade de Dussel e a socialização do poder de Quijano. Sendo a transmodernidade uma ideia que coloca a diversidade enquanto projeto universal e enfatiza que não se deve ter uma visão ingênua e monolítica de cultura, pois há diversas assimetrias que não podem ser ignoradas.

Portanto, a democracia a partir de uma perspectiva transmoderna seria um diálogo transversal entre críticos de cada cultura, levando em consideração as assimetrias existentes entre os diferentes atores envolvidos (DUSSEL, 2001). Enquanto a socialização do poder de Quijano reitera a necessidade de um novo imaginário universal anticapitalista radical que descolonize as perspectivas marxistas dos seus limites eurocêntricos. Com isto, entende-se que a narrativa comum deveria ser anticapitalista, antipatriarcal, anti-imperialista e contra a colonialidade do poder (GROSFOGUEL, 2008). Caso não ocorra uma mudança na perspectiva, 
com uma abrangência mais transmoderna, corre-se o risco da socialização do poder tornar-se mais um projeto universal abstrato contundente com o desenho global atual.

Ressalta-se que embora partam de um movimento de intelectuais latino-americanos que têm como principal força orientadora a realidade cultural e política específica da América Latina (ESCOBAR, 2003), os estudos decolonais mantém a importância de estabelecer um diálogo com as diferentes lutas anticoloniais e decoloniais presentes em outras regiões do Sul Político e que também representam uma crítica à modernidade eurocentrada (GROSFOGUEL, 2012). Argumenta-se, no entanto, que essas aproximações entre lutas anticoloniais para além da América Latina não se encontram suficientemente elaboradas entre os estudos decoloniais, sendo Ramón Grosfoguel (2008; 2012) um dos poucos autores do Grupo Modernidade/Colonialidade atualmente dedicados a estabelecer esses diálogos de maneira mais explícita e articulada.

\section{Revolução de Rojava}

Em 2015, o cantão de Kobane, na região autônoma de Rojava no norte da Síria, atraiu atenção internacional ao retomar territórios que haviam sido capturados pelo Estado Islâmico. O fato do cerco ter sido realizado por um exército - o YPJ (Unidade de Defesa Popular das Mulheres) - formado majoritariamente de combatentes mulheres fez com que os olhares para a região se mostrassem ainda mais curiosos. De outro lado, chamava atenção também o sistema organizativo no qual essa região estava inserida, que não seguia protocolos estatais e negava a própria estrutura do Estado-nação. Contudo, a resistência do Curdistão remete à períodos antecedentes a Guerra na Síria ou o aparecimento do Estado Islâmico.

A região do Curdistão historicamente foi - e ainda é - alvo de intervenções externas das mais variadas. É a partir da resistência a essas dominações e da tentativa de organizar um modelo de organização política alternativo - que não se limitasse a reproduzir as iniciativas já trilhadas no Oriente Médio - que se chegou na atual Revolução de Rojava. Como colocado por Öcalan, “[...] os curdos vêm combatendo a colonização e a conquista de potências estrangeiras desde tempos imemoriais" (ÖCALAN, 2009, p. 7-8). No começo século XX, o Curdistão passou a sofrer um tipo particular de colonialismo que impacta a região até hoje. Impulsionado pelo enfraquecimento e dissolução do Império Otomano, potências europeias - em especial França e Reino Unido - adotaram uma posição fortemente intervencionista no Oriente Médio, recortando a região em diferentes Estados-nação através do Acordo de Sykes-Picot, que dividiu o território entre as duas potências. 
Excluídos da divisão estatal, os curdos tiveram seu território transpassado por quatro Estados: Turquia, Síria, Iraque e Irã, como mostra o mapa abaixo (figura 1). Em cada um desses países elites nacionais buscavam consolidar estruturas dos novos Estados e fortalecer um sentimento nacionalista interno, o que significou em uma repressão de manifestações de uma identidade curda. Öcalan (2009), nascido em território turco, salienta especialmente a violência das práticas assimilacionistas turcas que incluíam, entre outras medidas, a proibição do uso da língua curda no país.

Figura 1 - mapa da região do Curdistão.

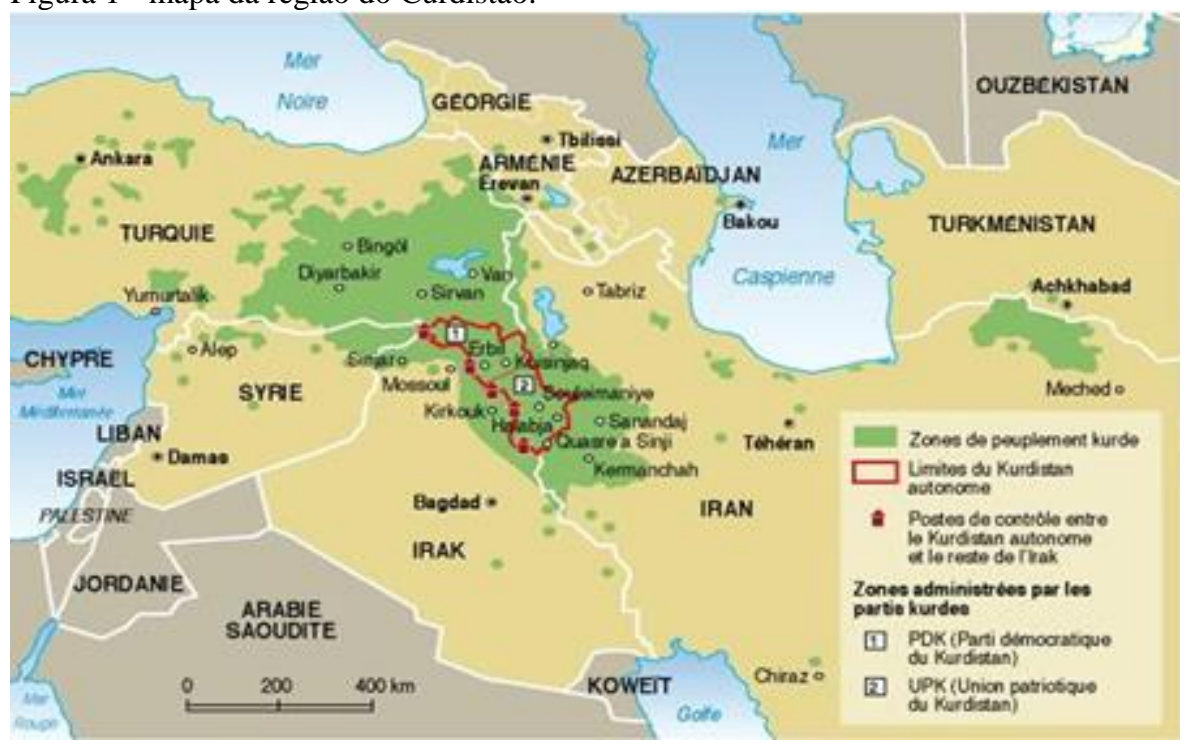

Fonte: Instituto curdo de Paris. 
Foi no Curdistão turco que emergiram boa parte das bases ideológicas e teóricas colocadas em prática na Revolução de Rojava. Foi a partir das experiências do Partido dos Trabalhadores do Curdistão (PKK) na Turquia que Öcalan formulou a ideia de Confederalismo Democrático, que mais tarde foi colocada em prática em Rojava, na parte síria do Curdistão. Preso em território turco desde 1999, Öcalan escreveu do cárcere diversas propostas de organização política para o Curdistão que acabaram encontrando espaço na revolução de Rojava.

Além de negar organizar-se como um Estado, o movimento do Curdistão também nega limitar-se a fronteiras definidas, apresentando-se como uma alternativa democratizante para todo o Oriente Médio. Para Öcalan, “A liberdade do Curdistão está ligada à democratização do Oriente Médio. Um Curdistão livre só é concebível como um Curdistão democrático" (ÖCALAN, 2014, p. 35, tradução nossa). Desse modo, a transformação mais ampla da região é vista como fundamental para assegurar uma mudança sistêmica a longo prazo que não pode ser alcançada apenas por intervenções políticas locais.

Todavia, a luta anti-colonial curda não se restringe à crítica ao Estado-nação e a colonialidade presente na sua estrutura; há um histórico de interesses hegemônicos que influenciam o jogo político que se mantém presente ainda hoje. É importante salientar que o Oriente Médio é um local geopoliticamente estratégico, onde há muitos interesses, em diferentes esferas e de diferentes potências, que colidem. Com a Guerra na Síria, esse jogo de xadrez tornou-se ainda mais complexo. Como foi enfatizado pela co-coordenadora do Conselho Democrático da Síria Ilham Ahmed (apud KNAPP; FLACH; AYBOGA, 2016) em 2014 "cada um dos países mais poderosos tem seu próprio plano para o futuro da Síria”. Neste sentido, as forças locais e regionais são de certa maneira obrigados a se submeter às forças internacionais em menor ou maior escala. Logo, a luta curda é contra o colonialismo presente na região e os seus frutos, sendo o Estado-nação um deles, como foi apontado pelos autores: "Desde meados dos anos 80, o movimento de libertação do Curdistão achou, com grande habilidade, o seu caminho no meio de um campo minado, sem se permitir ser explorado por nenhum dos poderes hegemônicos" (KNAPP; FLACH; AYBOGA, 2016, p. 257, tradução nossa).

É relevante observar que a crítica elaborada por Öcalan ao que se refere como imperialismo e colonialismo sofrido pelo Curdistão não se restringe somente a práticas de países ocidentais. Elas também abarcam as práticas dos recém formados Estados da região, que aderiram a uma alternativa modernizadora, nacionalista e capitalista-burguesa que forçou as instituições do Estado-nação sobre o Curdistão (ÖCALAN, 2009). É a partir dessa experiência com o Estado marcada pela exclusão que baseia-se a iniciativa curda de buscar uma organização 
política distinta, que não tome a forma de um Estado moderno. Afinal, como indaga Öcalan, "Não foram o nacionalismo e os Estados-nação que criaram tantos dos problemas do Oriente Médio?” (ÖCALAN, 2017, p. 10).

Questão enfatizada por Dirik (2016) quando ela aponta que a experiência de exclusão curda da ordem dos Estados-nacionais foi dupla: “[...] não só lhes foi negado o seu próprio Estado, eles foram simultaneamente excluídos dos mecanismos das estruturas estatais em seu entorno" (DIRIK, 2016, tradução nossa). No entanto, é essa mesma exclusão da ordem estatal que possibilitou a conservação de organização social baseada em um senso comunitário que hoje é incorporado pelo Confederalismo Democrático da Revolução de Rojava (DIRIK, 2016). Segundo Öcalan, “[...] O confederalismo democrático repousa sobre a experiência histórica da sociedade e sua herança coletiva. Não é um sistema político moderno arbitrário, mas, em vez disso, acumula história e experiência” (ÖCALAN, 2017, p. 22, tradução nossa).

A proposta do Confederalismo Democrático formulada por Öcalan pretende oferecer um sistema democrático em que diferentes grupos sociais se organizam de maneira autônoma para participar ativamente das tomadas de decisão de suas comunidades. A criação de conselhos locais, congressos populares e outras formas de participação direta na deliberação e decisão de questões locais são essenciais, nesse sentido, para gerar formas de organização política que não se baseiam na autoridade do Estado. O objetivo é colocar o povo no centro do processo decisório da sociedade, construindo assim uma forma de governo baseado na autogestão popular e evitando a centralização característica das estruturas estatais (ÖCALAN, 2009).

Com o intuito de subverter a dominação de um sistema que se institucionalizou globalmente se dá através de três pilares: democracia radical, igualdade de gênero e ecologia. Sendo assim, a organização política de Rojava tenta criar ferramentas disruptivas que questionem as estruturas do capitalismo, do patriarcado e do Estado, que parecem ser um resultado inevitável da civilização moderna, um componente do processo de desenvolvimento (USTUNDAG, 2016).

Vale ressaltar que Rojava surge em um contexto de guerra e embargos comerciais, fazendo com que os curdos tenham que se posicionar diplomaticamente frente aos atores internacionais, ao mesmo tempo em que devem apresentar internamente o Confederalismo Democrático como um sistema emergente eficaz. Desta forma, os cantões muitas vezes assumem o papel do Estado, coletando informações, criando sistemas sanitários e de educação, falando em nome da população e criando alternativas econômicas frente os desafios encontrados. Entretanto, apesar dos cantões terem funções similares as do Estado, a forma como se dá esse processo de representação é distinto (USTUNDAG, 2016). 
Desde janeiro de 2014, a partir de uma Declaração de Autonomia, ficou estabelecida a Administração Autônoma Democrática (DAA, sigla em inglês) nos cantões de Afrin, Cizîre e Kobane. Dentro desse sistema há três principais estruturas: o Conselho Legislativo, também denominado de Parlamento; o Conselho Executivo ou o "governo", no qual cada ministério tem participação do TEV-DEM; e as Municipalidades. Essa estrutura política e organizativa faz parte do Conselho Democrático da Síria, fundado em 2015, e do Sistema Federal do Norte da Síria/Rojava, declarado em março de 2016, e busca tem o intuito de desenvolver um modelo de democracia mais participativa e direta (DIRIK, 2016).

Ademais, o sistema proposto pelo Confederalismo Democrático presume uma representação das minorias étnicas, religiosas e de gênero nos papéis de tomada de decisão, que é fortalecido e sustentado pela colisão dos partidos políticos curdos, denominada TEV-DEM, tal como um sistema de co-administração. Isto é, há sempre um homem e uma mulher, sendo o homem eleito pela população em geral e a mulher apenas pelo eleitorado feminino. A ideia que envolve a co-coordenação se baseia em princípios simbólicos e práticos, pois descentraliza o poder e promove um consenso maior no que diz respeito às questões entre homens e mulheres (DIRIK, 2016). A figura abaixo mostra como funciona a estrutura da democracia direta implementada pelos curdos em Rojava: 
Figura 2 - Estrutura do confederalismo democrático em Rojava

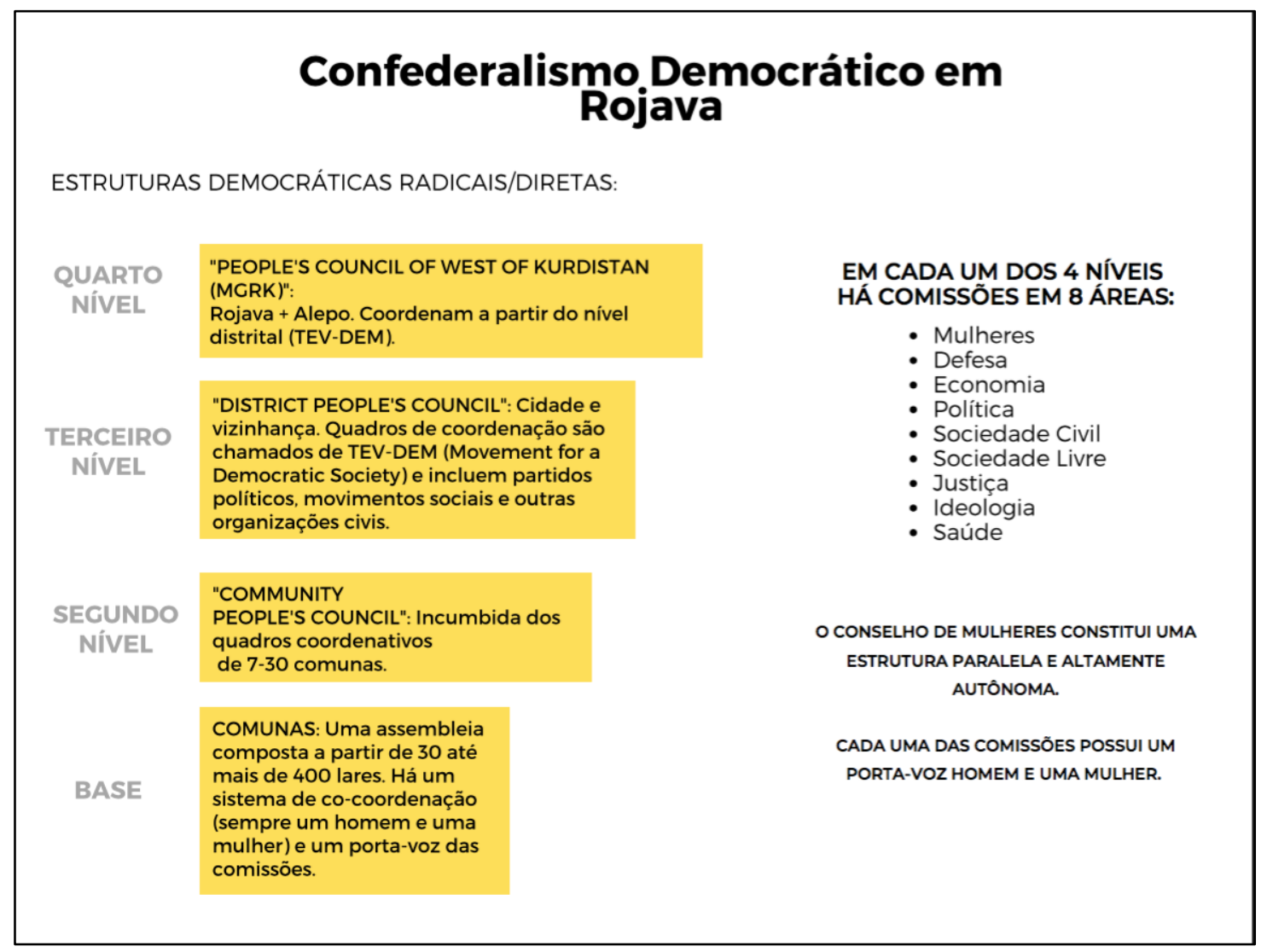

Fonte: Adaptado de KNAPP; FLACH; AYBOGA, 2016, 2016.

A base do sistema político curdo são as comunas, que são uma espécie de assembleia que reúne os moradores de uma determinada localidade. As comunas são responsáveis por delegar representantes para os Conselhos, pela organização da vida cotidiana e resolução de problemas mais corriqueiros - falta de energia, falta de professores em uma escola, etc. Os problemas só são delegados para o próximo nível quando eles não podem ser resolvidos na base ou transcendem as funções dos conselhos de primeiro nível (DIRIK, 2016). Com isso, o sistema implementado em Rojava conseguiu estabelecer um modelo de democracia mais direto e participativo, no qual a população busca solucionar os conflitos de baixo para cima, se distanciando da relação paternalista dos Estados. Sendo assim, o poder se mostra diluído entre diferentes conselhos e estruturas organizativas, não estando centrado em um único representante.

\section{Diálogos entre lutas do Sul}

Essa aproximação entre a reflexão decolonial latino-americana e a Revolução de Rojava é importante para que se avance na articulação entre movimentos não-hegemônicos de diferentes partes do mundo. Como argumenta Boaventura de Sousa Santos (2002, p. 265-6), 
"O potencial anti-sistêmico ou contra-hegemônico de qualquer movimento social reside na sua capacidade de articulação com outros movimentos, com as suas formas de organização e os seus objectivos". Para que essa articulação seja possível, o autor aponta que é necessário que esses movimentos tenham estabelecido uma inteligibilidade recíproca entre suas práticas e saberes. Só assim as experiências não-hegemônicas podem se transformar em alternativas contra-hegemônicas (SANTOS, 2002).

Essa inteligibilidade recíproca é alcançada pelo que Boaventura (2002) denomina de processo de tradução. É a partir dele que os movimentos sociais podem explorar o potencial de articulação uns com os outros. "O trabalho de tradução visa esclarecer o que une e o que separa os diferentes movimentos e as diferentes práticas de modo a determinar as possibilidades e os limites da articulação ou agregação entre eles" (SANTOS, 2002, p. 266).

O alcance da aproximação entre a Revolução de Rojava com a reflexão decolonial latino-americana aqui explorada apresenta suas limitações: como deixado claro por Boaventura (2002), os únicos capazes de realizar o processo de tradução são os próprios movimentos sociais, a partir de seus representantes. Portanto, o trabalho aqui desenvolvido limita-se essencialmente a destacar a importância de explorar o diálogo possível entre as experiências presentes na América Latina e no Curdistão a partir da ferida colonial que as une. É preciso ressaltar, ainda, que já existe uma aproximação entre Rojava e a América Latina realizada a partir de comitês de solidariedade ao povo curdo. Os comitês buscam dar apoio ao movimento e informar a população de outras regiões, traduzindo os textos originais para o espanhol e português, criando espaços para debates sobre o Curdistão na América Latina.

Essa aproximação exemplificada pelos comitês pode ser compreendida pelas semelhanças nas críticas ao sistema hegemônico vigente. Tanto na teoria decolonial quanto na Revolução de Rojava há um entendimento de que as formas de dominação trazidas pelo sistema capitalista não se restringem apenas ao âmbito econômico, mas se expressam em todas as esferas sociais, desde a organização política até as relações interpessoais cotidianas. Isto é, essas formas de dominação podem ser vistas tanto em casos de violências domésticas dentro de um núcleo familiar quanto nas relações entre diferentes regiões do sistema-mundo. Sendo assim, tanto os movimentos latino-americanos como a Revolução de Rojava buscam criar alternativas críticas à modernidade e às diversas formas em que ela se expressa. Para tanto, elas buscam ancorar-se nas experiências locais que haviam sido suprimidas pelo discurso eurocêntrico colonial.

Atenta-se, por outro lado, que a Teoria Decolonial e a proposta curda apresentam distinções em relação ao "alvo" da luta. De acordo com a perspectiva curda, enfatizada por 
Öcalan, o Estado seria a institucionalização do sistema patriarcal, capitalista e colonial, portanto, para modificar essa estrutura seria necessário acabar com o Estado. Em contrapartida, para a Teoria Decolonial o Estado é uma das formas de controle das relações sociais que compõe o atual padrão de poder mundial da modernidade/colonialidade. Esse padrão de poder mundial, segundo Quijano (2000), se baseia em quatro formas de controle social: o controle do trabalho, o controle do sexo, o controle da autoridade e o controle da subjetividade. Cada uma dessas formas de controle está sob a hegemonia de uma instituição, sendo elas, respectivamente, a empresa capitalista, a família burguesa, o Estado-nação e o eurocentrismo.

Assim, mesmo tendo uma relevância expressiva, o Estado é apenas uma das partes que sustentam o sistema moderno/colonial de acordo com a teoria decolonial. As questões de gênero e raça, a colonialidade e o capitalismo que fazem parte desse sistema devem ser enfrentadas, porém sem necessariamente partirem da dissolução do Estado. Já a proposta do Confederalismo Democrático dá uma maior centralidade ao Estado na sua crítica à modernidade: a dissolução do Estado-nação é colocada como uma pré-condição para o enfrentamento das diversas formas de opressões e dominações. É a partir da rejeição da organização estatal que a Revolução de Rojava pretende criar uma sociedade baseada na igualdade de gênero, na democracia radical e na ecologia.

\section{Considerações Finais}

Mesmo considerando as especificidades do contexto curdo, é possível criar aproximações entre a proposta da Revolução de Rojava e estudos decoloniais latinoamericanos. Há uma intenção explícita de buscar ressignificar o conceito de democracia a partir das experiências históricas curdas e de sua herança cultural, permitindo o que autores da Teoria Decolonial denominam de diálogo transmoderno, que questiona as noções estabelecidas pela modernidade (DUSSEL, 2016). Também nesse sentido há uma preocupação em buscar formas de organização política para o Curdistão que sejam distintas ao modelo eurocêntrico e moderno do Estado-nação (ÖCALAN, 2015), evitando as armadilhas colocadas aos movimentos anticoloniais e nacionalistas do Terceiro Mundo (GROSFOGUEL, 2012). A nova organização pretendida é assentada na busca pela autogestão dos espaços, permitindo uma participação popular mais direta nos rumos da Revolução de Rojava. Essa iniciativa pode ser relacionada com as observações de Quijano (2014) sobre a importância de uma "socialização do poder" nos processos revolucionários para evitar a concentração das decisões políticas em uma estrutura 
estatal hierárquica e para permitir que as massas tenham um efetivo controle sobre as instituições que regulam sua própria vida social cotidiana.

Ademais, é imprescindível ressaltar a importância de estabelecer estes vasos comunicantes entre o Sul Político, respeitando as particularidades de cada região, mas compreendendo a complexidade do sistema hegemônico no qual se está inserido. Tendo isto em vista, percebe-se que manter as lutas anticoloniais dentro dos ideais eurocêntricos se mostra pouco eficaz e um tanto quanto paradoxal. A experiência de Rojava no Curdistão, assim como as lutas indígenas e afro-americanas na América Latina mostram a necessidade de construir um discurso a partir do olhar do subalterno, fazendo uma crítica à modernidade e à todo o sistema que a sustenta.

Neste sentido, destaca-se a importância de entender que o capitalismo é um sistema hegemônico que perpassa todos os aspectos da vida e não está localizado apenas âmbito econômico. O desenvolvimento da sociedade, a organização social, a produção do conhecimento, a divisão do trabalho, as relações sociais, de gênero, a economia, a política foi pautada sob a perspectiva eurocêntrica (MIGNOLO, 2005). O que difere a proposta da Teoria Decolonial, assim como a do Confederalismo Democrático no Curdistão dos demais movimentos anticoloniais é essa busca por alternativas "afuera" do espectro de experiências ocidentalizadas, questionamentos as bases dessa estrutura hegemônica.

\section{Referências}

CASTRO-GÓMEZ, Santiago. Decolonizar la universidad - la hybris del punto cero y el diálogo de saberes. In: CASTRO-GÓMEZ, Santiago; GROSFOGUEL, Ramón (eds.). El giro decolonial: reflexiones para una diversidad epistémica más allá del capitalismo global. pp. 7991. Bogotá: Iesco-Pensar-Siglo del Hombre Editores, 2007.

DIRIK, Dilar. Building Democracy without the State. 2016. Disponível em: <https://roarmag.org/magazine/building-democracy-without-a-state/>. Acesso em: 12 fev. 2019.

DUSSEL, Enrique. Filosofía de la Liberación. 7. ed. México: Primero, 2001.

, Enrique. Transmodernidade e interculturalidade: interpretação a partir da filosofia da libertação. Sociedade e Estado, v. 31, n. 1, p. 51-73, 2016.

ESCOBAR, Arturo. Mundos y conocimientos de otro modo. Tabula Rasa, Bogotá, n. 01, p.51-86, jul. 2003.

GROSFOGUEL, Ramón. Para descolonizar os estudos de economia política e os estudos pós-coloniais: transmodernidade, pensamento de fronteira e colonialidade global. Revista Crítica de Ciências Sociais, n. 80, p. 115-147, 2008. 
Descolonizar as esquerdas ocidentalizadas: para além das esquerdas eurocêntricas rumo a uma esquerda transmoderna descolonial. Contemporânea- Revista de Sociologia da UFSCar, São Carlos, v. 2, n. 2, p. 337-362, 2012.

KNAPP, Michael; FLACH, Anja; AYBOGA, Ercan. Revolution in Rojava: Democratic Autonomy and Women's Liberation in Syrian Kurdistan. [s.i]: Pluto Press, 2016. 285 p.

MIGNOLO, Walter D. The Idea of Latin America. Blackwell Publishing, 2005.

ÖCALAN, Abdullah. Democratic Confederalism. Lulu Press, Inc, 2009.

War and Peace in Kurdistan: International Initiative Edition. Lulu Press, Inc, 2014.

QUIJANO, Aníbal. Colonialidad del poder, eurocentrismo y América Latina. In: LANDER, Edgardo (Org.). La colonialidad del saber: eurocentrismo y ciencias sociales - perspectivas latinoamericanas. Buenos Aires: CLACSO, 2000.

Don Quijote y los molinos de viento en América Latina. Departamento Ecuménico de Investigaciones. Revista Pasos, n. 127, p. 2-14, 2006.

Poder y Democracia en el Socialismo. In: Cuestiones y Horizontes: de la dependencia histórico-estructural a la colonialidad/descolonialidad del Poder. Buenos Aires: CLACSO, 2014.

SANTOS, Boaventura de Sousa. Para uma sociologia das ausências e uma sociologia das emergências. Revista crítica de ciências sociais, n. 63, p. 237-280, 2002.

, Boaventura de Sousa; MENESES, Maria. Introdução. In: SANTOS, Boaventura de Sousa; PAULA, Maria Meneses. Epistemologias do Sul. São Paulo: Cortez Editora, 2013.

ÜSTÜNDAG, Nazan. Self-Defense as a Revolutionary Practice in Rojava, or How to Unmake the State. South Atlantic Quarterly, [s.i], v. 115, n. 1, p.197-210, jan. 2016. 